\title{
Changes in the technological properties of sugar beet root crops during industrial storage in ventilated piles
}

\author{
Marina Egorova', Lyubov Puzanova, Lyudmila Smirnova, and Elena Leonteva \\ Federal Agricultural Kursk Research Center, 70b Karl Marks St. Kursk 305021, Russian Federation
}

\begin{abstract}
When storing sugar beets in natural conditions, transformations of the chemical composition occur in it, leading to the accumulation of non-sugars, which reduces the processing efficiency and sugar yield. The use of the technology of forced ventilation of the air environment of the kagats is aimed at reducing the negative impact of the ongoing processes. This study presents the results of changes in the technological properties of sugar beets during industrial storage of two types: in a ventilated rack, in a rack without ventilation. It was shown that forced ventilation of the air in the stagger led to slower development of diseases of root crops with stag rot, the processes proceeded 2 times slower. Changes in the chemical composition of sugar beets after 45 and 60 days of storage are shown. When sugar beets were stored in a ventilated stagger for 60 days, the daily decrease in sugar content was 1.6 times lower than when stored in a staggered rack without ventilation; the increase in the content of reducing substances is 3.5 times lower, $\alpha$-amino nitrogen, potassium, sodium - on average 1.2 times lower. The calculated sugar yield for the storage conditions of sugar beets in a ventilated trough was 1.1 times higher than when stored in a trough without ventilation. It has been established that the creation of more favorable conditions for the air environment of the sugar beet pile through forced ventilation reduces the intensity of natural biochemical and microbiological processes in root crops, extends the shelf life of their technological properties, and ensures the economic efficiency of sugar production.
\end{abstract}

\section{Introduction}

Sugar production in Russia has a long tradition, and for more than 200 years the main raw material has been sugar beet - a culture of a temperate climatic zone. Over the past 5 years, sugar production in the country has consistently exceeded 6 million tons and is the first result among countries that produce beet sugar. The continuation of this trend is possible provided that the sugar beet factories are competitive in the market. Various criteria of the competitiveness of beet sugar factories are given [1], among which there is a criterion for capacity utilization with raw materials for $120-150$ days of operation. For the conditions of Russia, depending on the region, this means storing sugar beets from 30 to 60 or more days; in the country as a whole, the volume of long-term storage of sugar beets reaches 20 million tons.

Sugar beetroots are stored in open areas in natural conditions in piles - an embankment that has a trapezoidal cross-section. The safety of root crops during storage is due to the influence of various factors, among which the physical environment of the kagata occupies a special place [2]. The optimal parameters of the physical environment of the kagat are: temperature $0 \ldots+5^{\circ} \mathrm{C}$, relative air humidity $92 \ldots 94 \%$, oxygen content $18 \ldots$ $20 \%$, carbon dioxide content $0.2 \ldots 0.5 \%$ [3]. Since the storage of sugar beets is carried out in natural conditions, the actual parameters of the physical environment of the kagats are influenced by the external environment, therefore they often differ from the optimal ones. During storage in root crops, physiological and biochemical processes associated with the maintenance of vital activity begin to occur, mainly the processes of hydrolytic decomposition of the carbohydrate complex, transformations of compounds of the nitrogen complex, the products of which affect the state of the air environment in the interroot space [2]. Storage is accompanied by developing under the influence of various bacteria and fungi in the air and on the surface of root crops [4], microbiological processes that enhance and accelerate the transformation of the components of technologically ripe sugar beet [5].

Transformations of the chemical composition lead to the accumulation of non-sugars [6], including reducing substances, $\alpha$-amine nitrogen, ash elements [7], the purity of the cell sap decreases. Such changes in the chemical composition of sugar beet have an extremely negative effect on the course of processing processes, require increased consumption of reagents for cleaning $[8,9]$, which reduces the efficiency of sugar beet processing and the yield of sugar.

The modern trend is the regulation of the parameters of the physical environment of the kagata by forced ventilation. This practice is used in the countries of North America, where natural climatic conditions contribute not only to cooling but also to freezing sugar beets $[2,10]$. The technology of storing sugar beet with

*Corresponding author: rniisp@gmail.com 
the use of forced ventilation of the air in the kagats is becoming more and more widespread in Russia as well. For this, various technical solutions are used to organize storage areas for sugar beets, equipped with fans, air ducts, as well as temperature control systems inside the piles $[11,12]$.

Data on changes in the chemical composition of sugar beets during long-term storage are given in articles by many authors, but they are devoted to one aspect, for example, the effect of the hybrid, storage temperature [13], the state of root crops, organizational storage methods [2, 10], shelf life [9]. Therefore, it is relevant to consider the results of industrial storage of sugar beets in conditions of forced ventilation of the air environment of the piles.

\section{Materials and methods}

\subsection{Storage}

The results of industrial storage of sugar beets were studied at a beet sugar plant located in the Kursk region in 2019 and 2020. At the beet sugar plant, two types of storage of sugar beets were used: A - in a ventilated kagat; B - in a hut without ventilation. Accordingly, the storage of sugar beets was carried out at two sites, of which one site - with a specially equipped forced ventilation system, the weight of the packed sugar beet was 200,000 tons; the second is the site of a kagat field with the storage of root crops in natural conditions, the weight of the laid sugar beet was 80,000 tons. Sugar beets from the 2019 harvest were stored from October 9 to 23, and the 2020 harvest from October 19 to November 1 . The estimated average date for laying sugar beets for storage was determined: October 17 in 2019 , October 26 in 2020. During the period of laying sugar beets in the piles, 5 samples were taken daily at each site. After 45 days and 60 days of storage, 5 samples of sugar beet were also taken per day.

\subsection{Analysis}

Sugar beetroots were analyzed by organoleptic and chemical parameters - the content of sucrose, reducing substances, potassium, sodium, $\alpha$-amino nitrogen. The organoleptic parameters of freshly dug beets were determined according to GOST 33884, after storage according to the developed method [8], the sugar content of root crops was determined according to the ICUMSA GS6-1 method. $\alpha$-amino nitrogen was determined according to the ICUMSA GS6-5 method, modified in terms of the preparation of working reagents, aliquots of the test solution, and working reagents during measurement [14]. The content of sodium and potassium was determined potentiometrically with ion-selective electrodes according to the corrected method [15], the content of reducing substances was determined according to [16].

The results obtained were processed by the methods of mathematical statistics, obtaining the average result per day, and then the average indicators were determined for the entire period of laying sugar beets for storage and after storage. The predicted sugar yield from sugar beets of a given quality was calculated according to the Braunschweig formula [17], assuming the standard loss of sucrose to molasses of $0.9 \%$. It is believed [13] that this formula is not suitable for stored sugar beets, since it does not take into account the increase in the content during storage of other non-sugars that reduce the sugar yield. However, in our study, we set out not to check the formulas, but to identify the trend in the change in the technological properties of sugar beets during storage.

\subsection{Meteorological conditions of vegetation and storage}

The meteorological conditions of the growing season of sugar beet in 2019 were generally favorable, which contributed to the accumulation of sucrose at least $18 \%$, however, due to heavy rainfall and subsequent hot dry weather on some plantations, soil over consolidation occurred locally, which could affect the architecture of root crops. The deficiency of moisture in the soil could create conditions under which microorganisms of the saprotrophic type of nutrition switch to parasitic nutrition [18], which carries the risk of developing various diseases, including root rot. During the period of harvesting sugar beets, laying in piles and during storage, warm weather prevailed, mainly with a lack of precipitation. The air temperature in NovemberDecember averaged $0.2 \ldots 2.5^{\circ} \mathrm{C}$, which is favorable for storing sugar beets in natural conditions.

During the growing season of sugar beet in 2020, mainly dry and warm weather prevailed with an average monthly temperature $1 \ldots 3{ }^{\circ} \mathrm{C}$ higher than the climatic norm, the amount of precipitation in June-July corresponded to the multi-year average monthly, in August-October it was $30 \ldots 60 \%$ of the average monthly rate. Warm dry weather promoted sugar accumulation in root crops; however, in August, the lack of moisture on some plantations contributed to overheating of the soil and its desiccation, which led to an increase in plant transpiration and loss of turgor in root crops. This situation carried the risk of reducing the quality of sugar beet and its keeping quality [19]. During the storage period of sugar beets, the prevailing weather was close to the climatic norm, with temperatures from $+2.3^{\circ} \mathrm{C}$ to $5.0^{\circ} \mathrm{C}$, favorable for storing sugar beets in natural conditions.

\section{Results and Discussions}

The sugar beetroots stored in 2019 were uniform in shape and size, with an average weight of $840 \mathrm{~g}$, healthy. $90 \%$ of root crops had minor injuries in the form of cuts and chips, $35 \%$ of root crops had a branching of the tail, in $50 \%$ of root crops the head was cut below the line of living petioles.

The sugar beetroots stored in 2020 were uniform in shape and size, with an average weight of $950 \mathrm{~g}$, healthy. All root crops had minor injuries in the form of cuts and chips, including the tail, $15 \%$ of root crops had a 
branching of the tail, in $20 \%$ of root crops the head was cut off below the line of living petioles.

In 2019, after 45 days of storage, all sugar beetroot crops, regardless of the type of storage, were diagnosed with clump rot at the initial stage. In sugar beet in ventilated piles, $7 \%$ of root crops were affected by vascular bacteriosis at the initial stage; the content of rotten mass in root crops was $0.7 \%$. In kagats without ventilation, $9 \%$ of root crops were affected by vascular bacteriosis at the initial stage; the content of rotten mass in root crops was $1.2 \%$.

Obviously, during the growing season, the prevailing meteorological conditions laid the foundation for the development of root rot. During the period of laying sugar beets for storage, the signs of this disease did not manifest themselves, since its feature is a latent nature [18], but at the same time such root crops quickly rot in clumps due to the high intensity of metabolic processes of the accompanying microflora.

After 60 days of storage of sugar beets, regardless of the type of storage, further development of clump rot and progression of the development of vascular bacteriosis were noted in all root crops. In sugar beet in ventilated piles, $10 \%$ of root crops were affected by vascular bacteriosis, in piles without ventilation - $15 \%$, the content of rotten mass was $3.1 \%$ and $5.9 \%$, respectively. These results confirm the low keeping quality of root crops with root rot. At the same time, the creation of close to optimal conditions of the air environment in the ventilated kagat slowed down the development of the disease.

In 2020, after 45 days of storage, all sugar beetroot crops, regardless of the type of storage, were also diagnosed with clump rot at the initial stage. The content of rotten mass in the sugar beet of ventilated piles was $0.8 \%$, and in piles without ventilation $-1.9 \%$. After 60 days of storage of sugar beets, regardless of the type of storage, further development of clump rot was noted in all root crops with an increase in the content of rotten mass, respectively, to $2.1 \%$ and $4.2 \%$. The meteorological conditions of the growing season worsened the keeping quality of root crops and clump rot developed more intensively than in 2019. However, these processes in ventilated kagats proceeded 2 times slower.

Thus, the creation of more favorable conditions for the air environment of the sugar beet pile due to forced ventilation allows slowing down the natural processes of a microbiological nature and extending the shelf life of raw materials for sugar production.

The chemical indicators of sugar beets of the 2019 harvest during storage and after storage are presented in Table 1, the 2020 harvest - in Table 2.

Table 1. Chemical composition of 2019 harvest sugar beet

\begin{tabular}{cccccc}
\hline $\begin{array}{c}\text { Type of } \\
\text { storage }\end{array}$ & $\begin{array}{c}\text { Sucrose } \\
\text { content, } \%\end{array}$ & $\begin{array}{c}\text { Content of } \\
\text { invert sugar, } \%\end{array}$ & $\begin{array}{c}\text { Content of } \\
\text { potassium, } \\
\text { mmol/kg }\end{array}$ & $\begin{array}{c}\text { Content of } \\
\text { sodium, } \\
\mathrm{mmol} / \mathrm{kg}\end{array}$ & $\begin{array}{c}\text { Content of } \\
\alpha \text {-amino nitrogen, } \\
\mathrm{mmol} / \mathrm{kg}\end{array}$ \\
\hline & $20.64 \pm 0.37$ & $0.08 \pm 0.01$ & $\begin{array}{c}\text { Sugar beet before storage } \\
2.55 \pm 0.18\end{array}$ & $0.62 \pm 0.12$ & $1.52 \pm 0.12$ \\
A & $19.76 \pm 0.28$ & $0.11 \pm 0.01$ & Sugar beet after 45 days of storage & $1.97 \pm 0.19$ \\
B & $18.79 \pm 0.31$ & $0.20 \pm 0.02$ & $3.43 \pm 0.31$ & $1.10 \pm 0.17$ & $2.15 \pm 0.33$ \\
A & $18.53 \pm 0.36$ & $0.20 \pm 0.02$ & Sugar beet after 60 days of storage & $1.28 \pm 0.19$ \\
B & $17.27 \pm 0.39$ & $0.64 \pm 0.07$ & $3.71 \pm 0.38$ & $1.33 \pm 0.27$ & $2.43 \pm 0.28$ \\
\end{tabular}

Table 2. Chemical composition of 2020 harvest sugar beet

\begin{tabular}{|c|c|c|c|c|c|}
\hline $\begin{array}{l}\text { Type of } \\
\text { storage }\end{array}$ & $\begin{array}{c}\text { Sucrose } \\
\text { content, \% }\end{array}$ & $\begin{array}{c}\text { Content of } \\
\text { invert sugar, \% }\end{array}$ & $\begin{array}{c}\text { Content of } \\
\text { potassium, } \\
\mathrm{mmol} / \mathrm{kg}\end{array}$ & $\begin{array}{l}\text { Content of } \\
\text { sodium, } \\
\mathrm{mmol} / \mathrm{kg}\end{array}$ & $\begin{array}{c}\text { Content of } \\
\alpha \text {-amino nitrogen, } \\
\mathrm{mmol} / \mathrm{kg}\end{array}$ \\
\hline & \multicolumn{5}{|c|}{ Sugar beet before storage } \\
\hline & $21.11 \pm 0.26$ & $0.08 \pm 0.01$ & $3.42 \pm 0.35$ & $1.15 \pm 0.14$ & $1.83 \pm 0.15$ \\
\hline & \multicolumn{5}{|c|}{ Sugar beet after 45 days of storage } \\
\hline A & $20.82 \pm 0.29$ & $0.16 \pm 0.01$ & $3.92 \pm 0.38$ & $1.29 \pm 0.06$ & $2.09 \pm 0.18$ \\
\hline B & $20.34 \pm 0.30$ & $0.27 \pm 0.02$ & $4.58 \pm 0.36$ & $1.55 \pm 0.13$ & $2.36 \pm 0.21$ \\
\hline & \multicolumn{5}{|c|}{ Sugar beet after 60 days of storage } \\
\hline A & $18.53 \pm 0.34$ & $0.22 \pm 0.02$ & $4.37 \pm 0.41$ & $1.56 \pm 0.19$ & $2.24 \pm 0.18$ \\
\hline $\mathrm{B}$ & $17.27 \pm 0.37$ & $0.51 \pm 0.06$ & $4.99 \pm 0.21$ & $1.71 \pm 0.10$ & $2.54 \pm 0.06$ \\
\hline
\end{tabular}

During storage, changes in the chemical composition of sugar beets took place. The sugar content of root crops decreased, while the content of reducing substances - the decomposition products of sucrose increased. A greater increase in the content of reducing substances corresponded to a greater decrease in the content of sucrose. The trend of a greater decrease in sugar content with an increase in shelf life, regardless of the type of storage, was observed in 2019 and 2020. However, the level and rate of decrease in sugar content for each day of storage in 2020 were lower compared to 2019. So, in 2019, after 60 days of storage, the sugar content of root crops decreased by $2.11 \%$ in a ventilated box, in a box without ventilation - by $3.37 \%$; in 2020 , respectively, by $1.40 \%$ and $2.19 \%$. The daily decrease in 
sugar content for 60 days of storage was $0.035 \%$ for root crops in a ventilated stack, and $0.056 \%$ in a stack without ventilation; in 2020, respectively, $0.022 \%$ and $0.037 \%$. Thus, the decrease in sugar content in the kagat without ventilation was, on average, 1.6 times greater. In turn, the growth rate of the content of reducing substances was also lower in 2020. After 60 days of storage of sugar beets in 2019, the content of reducing substances in a ventilated cage increased by $0.12 \%$, in a cage without ventilation - by $0.56 \%$; in 2020 , respectively, by $0.14 \%$ and by $0.43 \%$. The daily increase in the content of reducing substances in sugar beets in 2019 during storage in a ventilated cage was $0.002 \%$, in a cage without ventilation - $0.009 \%$; in 2020 , respectively, $0.002 \%$ and $0.007 \%$.

Such results of the consumption of sucrose during storage of sugar beets can be explained by a higher respiration rate in 2019 due to the presence of more injured root crops, the concomitant development of bacterial root rot. The comparison of the respiration rate of sugar beet under different types of storage indicates that more optimal conditions in ventilated piles were an advantage in reducing the consumption of sucrose for respiration.

The content of $\alpha$-amino nitrogen in sugar beets stored in a ventilated kagat in 2019 increased 1.3 times after 45 days of storage, and 1.6 times after 60 days; in a kagat without ventilation after 45 days - 1.4 times, after 60 days - 1.8 times. In 2020, the content of $\alpha$-amino nitrogen in sugar beets in a ventilated kagat increased 1.05 times after 45 days, and 1.1 times after 60 days; in a kagat without ventilation after 45 days - 1.2 times, after 60 days - 1.3 times. As can be seen, the increase in the content of $\alpha$-amino nitrogen in 2020 was lower. Since the increase in the content of $\alpha$-amino nitrogen in sugar beet is associated with the hydrolysis of high molecular weight nitrogen compounds - proteins and peptides [13, 20], in 2019 this process was more intensive due to the development of bacterial root rot [21]. Regardless of the year of research, less optimal conditions for sugar beets [22] in a clutch without ventilation contributed to an increase in the concentration of $\alpha$-amino nitrogen.

The potassium content in sugar beets during storage was changed as follows. In 2019, when storing sugar beets in a ventilated kagat, after 45 days, the potassium content increased 1.3 times, after 60 days - 1.6 times; during storage of sugar beets in a pile without ventilation, it increased by 1.5 and 1.9 times, respectively. In 2020, when storing sugar beets in a ventilated kagat, after 45 days, the potassium content increased 1.2 times, after 60 days - 1.2 times; during storage of sugar beets in a pile without ventilation increased by 1.2 and 1.4 times, respectively.

The sodium content in sugar beets during storage was changed as follows. In 2019, when storing sugar beets in a ventilated kagat, after 45 days, the sodium content increased 1.8 times, after 60 days - 2.1 times; when storing sugar beets in a pile without ventilation, it increased by 2.1 and 3.1 times, respectively. In 2020, when storing sugar beets in a ventilated kagat, after 45 days, the sodium content increased 1.1 times, after 60 days - 1.3 times; during storage of sugar beets in a pile without ventilation, it increased by 1.3 and 1.5 times, respectively.

An increase in the content of potassium and sodium in sugar beets during storage was also noted in the data of other researchers [20,22]. In our studies, it was confirmed that in ventilated kagats, these processes were slower. Consequently, the creation of more favorable conditions for storing root crops in ventilated kagats with sugar beets slows down the course of various biochemical processes in them, leading to a decrease in the content of sucrose and the accumulation of nonsugars. This extends the shelf life of the technological properties of sugar beet, which ensure the economic efficiency of sugar production.

The values of the predicted sugar yield are presented in Table 3.

Table 3. Sugar yield from sugar beet, $\%$

\begin{tabular}{ccc}
\hline $\begin{array}{c}\text { Type of } \\
\text { storage }\end{array}$ & 2019 & 2020 \\
\hline & \multicolumn{2}{c}{ Sugar beet before storage } \\
& 18.49 & 18.81 \\
& Sugar beet after 45 days of storage \\
A & 17.45 & 18.44 \\
B & 16.42 & 17.85 \\
& Sugar beet after 60 days of storage \\
A & 16.14 & 17.25 \\
B & 14.69 & 16.36 \\
\hline
\end{tabular}

The highest sugar yield is observed in freshly dug 2020 sugar beets due to their higher sugar content. The sugar yield from stored sugar beets is declining, with the magnitude of the decline in sugar yield in 2019 being higher than in 2020. The sugar yield after 45 days of storage in ventilated kagats in 2019 decreased by $1.04 \%$, and in 2020 - by $0.37 \%$; after 60 days of storage, respectively, by $2.35 \%$ and $1.56 \%$. The sugar yield after 45 days of storage in piles without ventilation in 2019 decreased by $2.07 \%$, and in 2020 - by $0.96 \%$; after 60 days of storage, respectively, by $3.80 \%$ and $2.45 \%$. A greater decrease in sugar yield in sugar beets stored in 2019 can be explained by the presence of root rot of root crops after vegetation, which affected all metabolic processes during storage, which were more intensive and led to an increase in the content of various non-sugars. The type of storage had the following effect on the sugar yield: the decrease in yield relative to freshly dug sugar beets when stored in piles without ventilation was approximately 1.5 times higher compared to the decrease in yield from beets stored in ventilated piles.

The data of other researchers have been confirmed $[6,9]$ that with an increase in the shelf life, the yield of sugar from sugar beet decreases. Our research has established that storage of sugar beets in ventilated piles allows you to maintain quality and provide a higher sugar yield compared to storage in natural conditions in piles without ventilation.

\section{Conclusion}

Long-term storage of sugar beets allows you to extend the sugar beet production season. At the same time, it is 
important to create optimal conditions for the air environment in the clamps. The use of forced ventilation of the air in the piles is one of the technologies that create optimal storage conditions for sugar beet, which has become widespread in Russia. The results of a study on the change in the technological properties of sugar beets during long-term storage in 2019 and 2020 showed the advantages of this type of storage. They are expressed in a slowdown in natural processes of a biochemical and microbiological nature, which leads to a decrease in the consumption of sucrose for respiration for 60 days concerning storage in piles without ventilation by 1.6 times, a decrease in the growth of the content of non-sugars: reducing substances - by 3.5 times, $\alpha$-amino nitrogen, potassium, sodium on average 1.2 times. The calculated sugar yield for the storage conditions of sugar beets in a ventilated cart was 1.1 times higher than when stored in a cart without ventilation, and the decrease in sugar yield concerning freshly dug beets was 1.5 times less for sugar beets stored in ventilated cartons compared to with storage in piles without ventilation. In general, the creation of more favorable conditions for storing root crops in ventilated stalls with sugar beets lengthens the shelf life of their technological properties, ensuring the economic efficiency of sugar production.

\section{References}

1. E.V. Ivanov, Sugar beet. 5, 2 (2020)

2. L.L. Van Eerd, K.A. Congreves, J.W. Zandstra, Can. J. Plant Sci. 92, 129 (2012)

3. N.M. Sapronov, M.K. Pruzhin, A.N. Morozov, D.M. Aksenov, Sugar. 8, 24 (2015)

4. L.A. Korobova, N.G. Kulneva, SPFP. 4, 79 (2020)

5. L.N. Putilina, N.A. Lazutina, V.B. Chernogil, SPFP. 2, 51 (2019)

6. M. Wojtczak, A. Antczak-Chrobot, P. Bak, M. Molska, I. Blaszczyk, A. Papiewska, Zuckerindustrie. 12 (141), 760 (2016)

7. L.N. Putilina, N.A. Lazutina, I.V. Cherepuhina, Technol. of food and proc. ind. of AIC - healthy food. 1, 15 (2019)

8. M.I. Egorova, L.N. Puzanova, L.Yu. Smirnova, SPFP. 3, 134 (2020)

9. V.I. Kostin, F.A. Mudarisov, S.N. Reshetnikova, I.L. Fedorova, Sugar beet. 5, 2 (2020)

10. K. Farahmand, V. Khiabani, N. Dharmadhikari, A. Denton, IJRES. 1(4), 11 (2013)

11. A.I. Zavrazhnov, N.V. Zuglenok, A.A. Zavrazhnov, S.S. Tolstoshein, S.M. Koltsov, IOP Conf. Series: Materials Sci. and Eng. 919, 062067 (2020)

12. V.V. Popov, N.M. Martynjuk, Sugar. 9, 22 (2017)

13. C. Kenter, C. Hoffman, Int. J. Food Sci. Technol. 44, 910 (2009)

14. V.N. Kuhar, A.P. Chernyavsky, L.I. Chernyavskaya, Yu.A. Mokanyuk, Sugar. 4, 42 (2019)
15. M.I. Egorova, L.N. Puzanova, L.Yu. Smirnova, IOP Conf. Series: Earth and Envir. Sci. 640, 052026 (2021)

16. Methods for determining the chemical composition and quality indicators of sugar beet (RNIISP, Kursk, 2001)

17. K. Buchholz, B. Märländer, H. Puke, H. Glattkowski, K. Thielecke, Zuckerindustrie. 2 (120), 113 (1995)

18. J. Mansfield, S. Genin, S. Magori et al., Molecular plant pathology. 13 (6), 614 (2012)

19. D. Shpaar, D. Draeger, A. Zakharenko et al., Sugar beet. Growing, harvesting and storage (Orekh, Minsk, 2004)

20. Ye.V. Zheryakov, S.A. Kotlov, Volga Reg. Farmland. 3 (44), 27 (2017)

21. N.G. Kulneva, L.N. Putilina, M.V. Zhuravlev, I.G. Selezneva, Actual biotech. 4 (15), 12 (2015)

22. Ye.V. Zheryakov, Volga Reg. Farmland. 4 (45), 48 (2017) 